\title{
The Utility of Pre operative Serum Thyroid Stimulating Hormone Level For Predicting Malignancy in Nodular Thyroid Disease And Their Clinical Study
}

\author{
P. Rajendra kumar ${ }^{1}$, Dr.divakar shenoy ${ }^{2}$ \\ ${ }^{I}$ Resident In General Surgery ${ }^{2}$ Professor Of Surgery, K.S.Hegde Medical Academy \\ Dwarakamayee Kutharpadav, Munnur Post, Mangalore India
}

\begin{abstract}
Many patients present to the surgical department with a thyroid nodule. However not all require surgery and only 5-6\% of these are malignant. There are many methods to diagnose and predict malignancy in a thyroid nodule. This study throws light on the usefulness of TSH (thyroid stimulating hormone) estimation and its role in predicting malignancy. This is a prospective study involving 100 patients admitted to our hospital with thyroid swellings suspicious of malignancy. The objective was to evaluate the utility of serum TSH (thyroid stimulating hormone) estimation as a biochemical predictor of malignancy in suspicious thyroid nodules and to study the clinical presentation of thyroid malignancies.The mean preoperative TSH value was $2.39 \pm 1.42 \mathrm{mU} / \mathrm{L}$. Mean TSH value in malignancy was higher $(3.71 \pm 1.22 \mathrm{mU} / \mathrm{L})$ compared to those with benign disease $(1.80 \pm 1.03 \mathrm{mU} / \mathrm{L})$. Incidence of malignancy increased with higher TSH values. We concludedin our study the utility of pre-operative serum TSH level as a predictor of malignancy and it showed statistically significant ( $p$ $<0.01)$ between higher TSH levelsand malignant nodules. TSH levels could be used as predictor in clinically suspect malignant thyroid swelling with a benign FNAC (fine needle aspiration cytology) report. In such cases where TSH value is high, the FNAC (fine needle aspiration cytology) can be relocked to confirm the diagnosis.

Keywords: Thyroid stimulating hormone fine needle aspiration cytology, histopathology, thyroid malignancies ,papillary follicular malignancies.
\end{abstract}

\section{Introduction}

Thyroid diseases have always been an enigma. The management of thyroid diseases has undergone a tremendous change over the ages, from the crude surgeries of the ancient times to the multidisciplinary approach of the modern era. However in the present scenario surgery still plays an important role especially in the management of thyroid malignancies. Thyroid malignancies account for $90 \%$ of endocrinal malignancies. The incidence of thyroid malignancies has increased three fold over the past 3 decades. Many patients present to the surgical outpatient department with a thyroid nodule. However not all these patients require surgery as only 5$6 \%$ of these are malignant ${ }^{[11,12]}$. There are many methods to diagnose and predict malignancy in a thyroid nodule. A clinical examination is always the first step to assess a nodule. A thyroid profile is also essential. This is accompanied by certain tests which increase the rate of detection. Fine needle aspiration cytology (FNAC) is the present gold standard and primary tool for assessing risk of malignancy ${ }^{[1]}$. Other tests include ultrasonography, thyroid scintigraphy, CT scan(computer tomography) and MRI(magnetic resonance imaging). Recent studies have found levels of serum TSH to be an independent predictor of malignancy in thyroid nodules ${ }^{[2,3,5]}$.This biochemical marker could be used as a screening test for malignancy. In this study we investigated the utility of TSH in predicting malignancy and the common clinical presentation of thyroid malignancies.

\section{Methodology}

This isan prospective study conducted at Justice K.S.Hegde Charitable Hospital, Deralakatte, Mangalore, Karnataka, India. It was done after obtaining ethical committee approval from September 2014 to September 2016. A total of 100 patients were included into the study. Inclusion CriteriaCases presenting with Thyroid swelling, Age more than 18 years, Cases must be clinically euthyroid,FNAC should be done in all cases. Exclusion Criteria Those cases not in euthyroid state, Patients not willing for FNAC and surgery, Patients in whom TSH levels obtained while on thyroid hormone therapy. Thyroid lymphomas, thyroiditis, Gravesdisease, Patient with a final pathological diagnosis of medullary thyroid carcinoma.METHODAproforma is designed for the study. Data will be collected by personal interview or hospital records.Thyroid swelling examination will be done.From these patients preoperative TSH levels will be measured.TSH will be compared with the histopathological report after thyroid surgery and their management follow up will be done. 


\begin{tabular}{|l|l|l|l|}
\hline My Study & $\begin{array}{l}\text { Chennai Cancer } \\
\text { Institute }^{[17]}\end{array}$ & Fiore Et Al & Haymart Et Al ${ }^{[1]]}$ \\
\hline 41 & 40 & 45 & 46 \\
\hline
\end{tabular}

\section{Results}

This is a prospective study involving 100 patients admitted to our hospital with thyroid swellings suspicious of malignancy. The objective was to evaluate the utility of serum TSH estimation as a biochemical predictor of malignancy in suspicious thyroid nodules and to study the clinical presentation of thyroid malignancies. The observations of this study can be summarized as follows

Most patients were females with mean age of $44.2 \pm 15.3$ years. Mean age of malignancy was 40 years with a higher mean age in males, as compared to females. Commonest presentation was a rapidly growing thyroid swelling of short duration. In some cases there was history of a longstanding goiter with sudden development of secondary symptoms such as pain and compressive symptoms.Majority of patients presented with a SNG (solitary nodular goiter). The incidence of malignancy was higher inSNG (solitary nodular goiter) (35\%) compared to MNG (multinodular goiter) (33.33\%). 4 patients presented with primary complaints other than a neck swelling. 2 patients $(4 \%)$ presented with cystic swelling of neck which turned out to be cervical lymph node metastasis. The incidence of neck nodes was $15 \%$ and distant metastasis was $1 \%$. $20 \%$ of patients had FNAC positive for malignancy with $2 \%$ doubtful results.Papillary carcinoma was the most common histopathological type. The mean preoperative TSH value was $2.39 \pm 1.42 \mathrm{mU} / \mathrm{L}$. Mean TSH value in malignancy was higher $(3.71 \pm 1.22 \mathrm{mU} / \mathrm{L})$ compared to those with benign disease $(1.80 \pm 1.03 \mathrm{mU} / \mathrm{L})$. Incidence of malignancy increased with higher TSH values.

\section{Discussion}

In this study we had a total of 100 patients who presented with clinical features suspicious of thyroid malignancy. The main objective was to evaluate the role of TSH as a biochemical predictor of malignancy. Only patients that were euthyroid were included. A descriptive analysis of the clinical presentation and management was done. The observations and results were subjected to statistical analysis and compared with other studies.

\section{Gender Distribution}

84 female patients and 16 male patients were included in the study. 34 out of 100 patients had proven malignancy.

\begin{tabular}{|l|l|l|l|l|}
\multicolumn{7}{|c|}{ Sex Distribution Of Malignant Cases } \\
\hline My Study & Jemal Et Al ${ }^{[16]}$ & Dorairajan Et Al ${ }^{[17]}$ & $\begin{array}{l}\text { Chennai Cancer } \\
\text { Et Al }\end{array}$ & $\begin{array}{l}\text { P } \\
\text { Value }\end{array}$ \\
\hline $3: 1$ & $3: 1$ & $3.5: 1$ & $3.2: 1$ & $<$ \\
\hline
\end{tabular}

Thyroid disease are more common in females and also thyroid carcinoma more in female sex.

\section{Mean Age Of Malignancy}

\section{Age Distribution}

$>18-85$ years age group included in this study and mean age was $43+/-12.12$ years.

$>$ Mean age of thyroid malignancy was 41 years.

\section{Risk Factors}

In my study no patient had history of exposure to goitrogens ionizing radiation, high iodine diet nor family history and incidence of cancer more in extremes of age. There was higher incidence of malignant nodules in male patients similar to Haymart, et $\mathrm{al}^{[3]}{ }^{[3}$. Hence, male sex is a risk factor for cancer thyroid ${ }^{[11,12]}$. Comparision Between Incidence Of Maliganant And Non Malignant Nodules According To Gender 
The Utility Of Pre Operative Serum Thyroid Stimulating Hormone Level For....

\begin{tabular}{|c|c|c|c|c|c|}
\hline GENDER & $\begin{array}{l}\text { HAYMART } \\
\text { ETAL }\end{array}$ & & MY STUDY & & \\
\hline & $\begin{array}{l}\text { NO } \\
\text { MALIGNANC } \\
\text { YN }=(602)\end{array}$ & $\begin{array}{l}\text { MALIGNANC } \\
\text { Y N = (241) }\end{array}$ & $\begin{array}{l}\text { NO } \\
\text { MALIGNANC } \\
\text { YN = (66) }\end{array}$ & $\begin{array}{l}\text { MALIGNANC } \\
\text { Y N }=(34)\end{array}$ & P VALUE \\
\hline MALE & 99 & 63 & 8 & 8 & 0.01 \\
\hline FEMALE & 503 & 178 & 58 & 26 & 0.01 \\
\hline
\end{tabular}

\section{Duration Of Disease}

Most patients presented with rapidly growing thyroid swellings of duration of 12 years. Some patients had goitre for more than a decade and presented with a recent change in size or appearance of certain new symptoms. A sudden rapid increase in the size of a thyroid swelling or any compressive symptoms such as dyspnea, dysphagia, dysphonia or Horner's syndrome is suggestive of a malignant change.

\section{Comparision Of Duration Of Disease}

\begin{tabular}{|l|c|}
\hline \multicolumn{1}{|c|}{ STUDY } & AVERAGE DURATION OF THYROID SWELUNG \\
\hline MAZZAFERRI ETAL & 5 - 10 YEARS \\
\hline DORAIRAJAN ETAL & $3-4$ YEARS \\
\hline OUR STUDY & 5 -TYES.RS \\
\hline
\end{tabular}

\section{Clinical Features}

Swelling is the major complaint in our study most of them presented with multinodular goiter remaining presented with solitary nodule goiter. Few presented with pain and discomfort. In our study cancer rates are higher in SNG (35\%) when compared to multinodular goiter(33.3\%).

\section{Lymph Node Metastasis}

33 to $61 \%$ of patients with papillary carcinoma will have involvement of cervical lymph nodes at the time of diagnosis $^{[6]}$.

Cervical Lymph Node Involvement

\begin{tabular}{|l|l|l|l|}
\hline My Study & Mazzaferri Et Al ${ }^{[18]}$ & Dorairajan Et Al ${ }^{[17]}$ & $\begin{array}{l}\text { Chennai } \\
\text { Cancer } \\
\text { Institute }\end{array}$ \\
\hline $15 \%$ & $33-61 \%$ & $26-50 \%$ & $59 \%$ \\
\hline
\end{tabular}

$>$ Presence of neck lymph nodes was significant clinical indicator of malignancy.

\section{Distant Metastasis}

The incidence of distant metastasis in this study was $1 \%$. This patient presented with metastasis to proximal part of left humerus and compression fracture of sixth cervical vertebra.

Comparison Of Incidence Of Distant Metastasis

\begin{tabular}{|l|l|l|l|}
\hline My Study & Chennai Cancer Institute ${ }^{[3]]}$ & Dorairajan Et Al ${ }^{[37]}$ & ${\underset{ }{[41]}}^{\text {Mazzaferri Et }} \quad \mathbf{A l}$ \\
\hline $1 \%$ & $8 \%$ & $5 \%$ & $1 \%$ \\
\hline
\end{tabular}




\section{Histopathology}

In our study all were well differentiated carcinoma $77 \%$ were papillary carcinoma $23 \%$ were follicular carcinoma.

\begin{tabular}{|c|c|c|}
\hline & \multicolumn{2}{|c|}{ Comparison Of Histopathological Type Of Malignancy } \\
\hline & PAPILLARY CARCINOMA & FOLLICULAR CARCINOMA \\
\hline MY STUDY & $77 \%$ & $23 \%$ \\
\hline HAYMART ET AL & $87 \%$ & $7 \%$ \\
\hline $\begin{array}{c}\text { MAZZAFERRI ET } \\
\text { AL }\end{array}$ & $60 \%$ & $20 \%$ \\
\hline BAILEY AND LOVE & $80-85 \%$ & $10 \%$ \\
\hline DEVITA ETAL & $70-80 \%$ & $10 \%$ \\
\hline
\end{tabular}

\section{Tsh Levels And The Risk Of Malignancy}

In this study the mean preoperative TSH value was: $2.39 \pm 1.42 \mathrm{mU} / \mathrm{L}$. All patients were euthyroid. The mean TSH value was significantly higher in malignancy than in benign disease i.e. $3.71 \pm 1.22 \mathrm{mU} / \mathrm{L}$ vs. $1.80 \pm 1.03 \mathrm{mU} / \mathrm{L}$. This is comparable to the results of Haymart et al ${ }^{[3]}$, Fiore et al ${ }^{[19]}$ and Jonklaas et al ${ }^{[14]}$.

\begin{tabular}{|l|l|l|l|}
\hline \multicolumn{4}{|c|}{ Comparison Of Mean Tsh Value In Benign Vs Malignant Disease } \\
\hline MY STUDY & BENIGN & MALIGANANT & P VALUE \\
\hline HAYMART ET AL & $1.80+-1.03$ & $3.71+-1.62$ & $\mathrm{P}<0.001$ \\
\hline FIORE ET AL & $1.4+-0.4$ & $3.7+-2.3$ & $\mathrm{P}<0.001$ \\
\hline
\end{tabular}

On analysis of the preoperative TSH values it was observed that TSH level was an independent predictor of malignancy. Patients with values of $0.40-1.39 \mathrm{mU} / \mathrm{L}$ had $0 \%$ chance of malignancy. Those with range of $1.40-4.99 \mathrm{mU} / \mathrm{L}$ had $36.7 \%$ chance of malignancy whereas those with TSH levels $>5 \mathrm{mU} / \mathrm{L}$ had $75 \%$ chance of malignancy.

Ethical approval: "All procedures performed in studies involving human participants were in accordance with the ethical standards of the institutional ethics committee and with the 1964 Helsinki declaration and its later amendments or comparable ethical standards."

Informed consent: Informed consent was obtained from all the participants included in the study

\section{References}

[1]. Williams NS, Bulstrode CJK, O'Connell PR, The Thyroid and Parathyroids, Bailey \& Love's Short Practice of Surgery, 25th ed. New York: Arnold;

[2]. Boelaert K, Horacek J, Holder RL, et al., Serum thyrotropin concentrationvas a novel predictor of malignancy in thyroid nodules investigated by fine needle aspiration, J. Clin Endocrinal Metab, 2006; 91:4295-4301

[3]. Haymart MR, Repplinger DJ, Leverson GE, et al, Higher TSH level in thyroid nodule patients is associated with greater risks of differentiated thyroid cancer and advanced tumor stage, J Clin Endocrinal Metab, 2008;93:809-14

[4]. Gupta $\mathrm{M}$ et al, Correlation of Fine Needle Aspiration Cytology with Histopathology in the diagnosis of Solitary Thyroid Nodule, Journal of Thyroid Research, Feb 2010;

[5]. Stergios A. Polyzos, Marina Kita, Zoe Efstathiadou et al, Serum thyrotropinconcentration as a biochemical predictor of thyroid malignancy in patients presenting with thyroid nodules, J Cancer Res ClinOncol. 2008; 134:953-96

[6]. DeVita VT, Lawrence TS, Rosenberg SA, DeVita, Hellman, and Rosenberg's Cancer Principles \& Practice of Oncology, 8th edition, Wolters Kluwer/Lippincott Williams \& Wilkins.

[7]. Mohamed Arafat, Sameshgalr, Ibrahim A etal, to evaluate relation between TSH and development of malignancy in nodular thyroid disease, Journal of Arab society for medical research 2014:9:28-32.

[8]. BA Satyanarayana, Ramachandra, Saurab Kumar Sinha et al, clinical study of thyroid malignancies and role of serum TSH in predicting malignancies in nodular thyroid disease, Journal of evolution of medical and dental sciences, 2013/vol 2/iss 43/ page 8386-8

[9]. Hegedus L 2004 Clinical practice. The thyroid nodule. N Engl J Med 351:1764-1771.

[10]. Mandel SJ 2004 A 64-year-old woman with a thyroid nodule. JAMA 292:2632-2642.

[11]. Ross DS: Evaluation and nonsurgical management of thyroid nodule. Randolph Surgery of the thyroid and parathyroid glands. Saunders 2003.

[12]. Mehanna HM, Jain A, Morton RP, Watkinson J, Shaha A: Investigating the thyroid nodule. BMJ 2009, 338:705-709.

[13]. Mazzaferri EL 2000 Thyroid cancer and Graves' disease: the controversy 10years later. EndocrPract 6:221-225 
[14]. Jonklaas J, Sarlis NJ, Litofsky D, Ain KB, Bigos ST, Brierley JD, Cooper DS, Haugen BR, Ladenson PW, Magner J, Robbins J, Ross DS, Skarulis M, Maxon HR, Sherman SI 2006 Outcomes of patients with differentiated thyroid carcinoma following initial therapy. Thyroid 16:1229-124

[15]. Braga M, Ringel MD, Cooper DS 2001 Sudden enlargement of local recurrent thyroid tumor after recombinant TSH administration. J ClinEndocrinolMetab 86:5148-515

[16]. Jemal A, Siegel R, Ward E, et al. Cancer statistics, 2007. CA Cancer J Clin 2007:57:43.

[17]. Dorairajan N, Pandiarajan R, Yuvaraja S. A descriptive study of papillary thyroid carcinoma in a teaching hospital in Chennai, India.Asian J Surg.2002 Oct;25(4):30

[18]. Mazzaferri EL, Jhiang SM. Long-term impact of initial surgical and medical therapy on papillary and follicular thyroid cancer. Am J Med 1994; 97:418.

[19]. Fiore E, Rago T, Provenzale MA, Lower levels of TSH are associated to a lower risk of papillary thyroid cancer in patients with thyroid nodular disease: thyroid autonomy may play a protective role. Endocrine-Related Cancer 16 1251-1260. 